\title{
Author Correction: Functional mitral regurgitation: should all valves be replaced?
}

\section{Maurizio Taramasso and Francesco Maisano}

Nature Reviews Cardiology (2016) https://doi.org/10.1038/nrcardio.2015.206 Published online 04 January 2016

In the version of this article initially published online and in print, the following competing interests were not declared. M.T. declares that he is consultant for 4Tech, Abbott Vascular and Boston Scientific; has received personal fees from CoreMedic, Edwards Lifesciences, Mitraltech and SwissVortex; and is a shareholder of 4Tech. F.M. declares that he has received grants and/or research support from Abbott, Biotronik, Boston Scientific, Edwards Lifesciences, Medtronic, NVT and Terumo; has received consulting fees and/or honoraria from Abbott, Cardiovalve (Mitraltech), Edwards Lifesciences, Magenta, Medtronic, Perifect, SwissVortex, Transseptal Solutions and Xeltis; has received royalty income and/or intellectual property rights from Edwards Lifesciences; and is a shareholder of 4Tech, Cardiogard, Magenta, Occlufit, Perifect, SwissVortex and Transseptal Solutions.

https://doi.org/10.1038/s41569-020-0415-7 I Published online 2 July 2020

(c) Springer Nature Limited 2020

\section{Author Correction: Clonal haematopoiesis: connecting ageing and inflammation in cardiovascular disease}

Siddhartha Jaiswal and Peter Libby (D)

Nature Reviews Cardiology (2020) https://doi.org/10.1038/s41569-019-0247-5 Published online 12 August 2019

In the version of this article initially published online and in print, Peter Libby's declaration of competing interests was incomplete. This error has been corrected for the HTML and PDF versions of the article.

https://doi.org/10.1038/s41569-020-0414-8 I Published online 2 July 2020

๑) Springer Nature Limited 2020 